\title{
Dynamics on the Pre-periodic Components of the Fatou Set of Three Transcendental Entire Functions and Their Compositions
}

\author{
Bishnu Hari Subedi ${ }^{{ }^{*}}$ and Ajaya Singh ${ }^{l}$ \\ ${ }^{I}$ Central Department of Mathematics, Institute of Science and Technology, \\ Tribhuvan University, Nepal \\ *Corresponding Author \\ subedi.abs@gmail.com, subedi_bh@cdmathtu.edu.np
}

\section{Abstract}

We prove that there exist three transcendental entire functions that can have an infinite number of domains which lie in the pre-periodic component of the Fatou set each of these functions and their compositions.

\section{Keywords}

Fatou set, carleman set, periodic component, pre-periodic component

\section{Introduction}

We denote the complex plane by $\mathbb{C}$, extended complex plane by $\mathbb{C}_{\infty}$ and set of integers greater than zero by $\mathbb{N}$. We assume the function $\mathrm{f}: \mathbb{C} \rightarrow \mathbb{C}$ is an entire function unless stated otherwise. For any $\mathrm{n} \in \mathbb{N}, \mathrm{f}^{n}$ always denotes the nth iterate of $\mathrm{f}$. If $\mathrm{f}^{\mathrm{n}}(\mathrm{z})=\mathrm{z}$ for some smallest $\mathrm{n} \in \mathbb{N}$, then we say that $\mathrm{z}$ is a periodic point of period $\mathrm{n}$. In particular, if $\mathrm{f}$ $(\mathrm{z})=\mathrm{z}$, then $\mathrm{z}$ is a fixed point of $\mathrm{f}$. If $\mid\left(\mathrm{f}^{\mathrm{h}}(\mathrm{z})\right)^{\prime}$ $\mid<1$, where ' represents complex differentiation of $\mathrm{f}^{\mathrm{h}}$ with respect to $\mathrm{z}$, then $\mathrm{z}$ is called an attracting periodic point of the function $\mathrm{f}$. A family $\mathcal{F}=\{\mathrm{f}$ :f is meromorphic on some domain $\mathrm{X}$ of $\left.\mathbb{C}_{\infty}\right\}$ forms normal family if every sequence (f) i $\in \mathrm{N}_{\mathrm{N}}$ of functions contains a subsequence which converges uniformly to a finite limit or converges to $\infty$ on every compact subset $\mathrm{D}$ of $\mathrm{X}$.

The Fatou set of $\mathrm{f}$, denoted by $\mathrm{F}(\mathrm{f})$, is the set of points $z \in \mathbb{C}$ such that sequence $\left(\mathrm{f}^{\mathrm{n}}\right)_{n \in \mathbb{N}}$ forms a normal family in some neighbourhood of $\mathrm{z}$. A maximally connected subset of the Fatou set F(f) is called a Fatou component. By definition, the Fatou set is open and may or may not be empty. Fatou set is non-empty for every entire function with attracting periodic points. The complement of the Fatou set is called Julia set and, is denoted by $\mathrm{J}(\mathrm{f})$. Classically, it is known that the sets $\mathrm{F}(\mathrm{f})$ and $\mathrm{J}(\mathrm{f})$ form a fundamental partition of the complex plane $\mathbb{C}$.

Let $\mathrm{U} \subset \mathrm{F}(\mathrm{f})$ (a Fatou component) such that $\mathrm{f}^{\mathrm{n}}(\mathrm{U})$ for some $\mathrm{n} \in \mathbb{N}$, is contained in some component of $F(f)$, which is usually denoted by $U_{n}$. A Fatou component $U$ is called preperiodic if there exist integers $n>m \geq 0$ such that $\mathrm{U}_{\mathrm{n}}=\mathrm{U}_{\mathrm{m}}$. In particular, if $\mathrm{U}_{\mathrm{n}}=\mathrm{U}_{0}=\mathrm{U}$ (that is, $\mathrm{f}^{\mathrm{n}}(\mathrm{U}) \subset \mathrm{U}$ ) for some smallest positive integer $\mathrm{n} \geq 1$, then $\mathrm{U}$ is called periodic Fatou component of period $\mathrm{n}$ and $\left\{\mathrm{U}_{0}, \mathrm{U}_{1} \ldots, \mathrm{U}_{\mathrm{n}-1}\right\}$ is called the periodic cycle. A component of Fatou set $F(\mathrm{f})$ which is not pre-periodic is called wandering domain.

Our particular interest of this paper is whether there are more than two transcendental entire functions that have a similarity between the dynamics of their compositions and the dynamics of each of these functions. Dynamics of two transcendental entire functions and their compositions were studied by Singh, (2003). $\mathrm{He}$ constructed some examples of transcendental entire functions where dynamics of individual functions vary primarily from the dynamics of their compositions. Also, he constructed some 
examples of transcendental entire functions where the dynamics of individual functions is similar to the dynamics of their compositions. Dinesh Kumar, et al. (2015) extended the results of Singh, (2003) in a certain sense, to the possibility of having two transcendental entire functions that can have infinitely many domains which may lie in the pre-periodic component of the Fatou set of each function and their compositions. We (2019) investigated three transcendental entire functions such that there are infinitely many domains which lie in the wandering components of the Fatou set of each function and their compositions. In this paper, we investigate three transcendental entire functions such that each of individual functions as well as their compositions consists of an infinite number of domains which lie in the pre-periodic component of each of functions and their compositions. In particular, we prove the following result.

Theorem 1: There exist three different transcendental entire functions $\mathrm{f}, \mathrm{g}$ and $\mathrm{h}$, and infinitelymany domains which lie in the different pre-periodic component of $\mathrm{F}(\mathrm{f})$, $\mathrm{F}(\mathrm{g}), \mathrm{F}(\mathrm{h}), \mathrm{F}(\mathrm{f} \circ \mathrm{g}), \mathrm{F}(\mathrm{g} \circ \mathrm{f}), \mathrm{F}(\mathrm{f} \circ \mathrm{h}), \mathrm{F}(\mathrm{g} \circ \mathrm{h})$, $\mathrm{F}(\mathrm{h} \circ \mathrm{f}), \mathrm{F}(\mathrm{h} \circ \mathrm{g}), \mathrm{F}(\mathrm{f} \circ \mathrm{g} \circ \mathrm{h}), \mathrm{F}(\mathrm{f} \circ \mathrm{h} \circ \mathrm{g}), \mathrm{F}(\mathrm{g} \circ \mathrm{f} \circ \mathrm{h})$, $\mathrm{F}(\mathrm{g} \circ \mathrm{h} \circ \mathrm{f}), \mathrm{F}(\mathrm{h} \circ \mathrm{f} \circ \mathrm{g})$ and $\mathrm{F}(\mathrm{h} \circ \mathrm{g} \circ \mathrm{f})$.

\section{Carleman Set}

To work out a Theorem 1, we need a notion in approximation theory of entire functions. In our case, we can use the notion of Carleman set from which we obtain an approximation of any holomorphic function by transcendental entire functions.

Definition 1 (Carleman set): Let $\mathrm{F}$ be a closed subset of $\mathbb{C}$ and $\mathrm{C}(\mathrm{F})=\{\mathrm{f}: \mathrm{F} \rightarrow \mathbb{C}: \mathrm{f}$ is continuous on $\mathrm{F}$ and analytic in the interior $\mathrm{F}^{\circ}$ of $\mathrm{F}$ \}. Then $\mathrm{F}$ is called a Carleman set (for C) if for any $\mathrm{g} \in \mathrm{C}(\mathrm{F})$ and any positive continuous function $\epsilon$ on $\mathrm{F}$, there exists entire function $\mathrm{h}$ such that $|\mathrm{g}(z)-\mathrm{h}(z)|<\epsilon$ for all $z \in \mathrm{F}$.

Nersesjan proved the following important characterization of Carleman set in 1971, but we cite this from the work of Gaier (1987).

Proposition 1: Let $\mathrm{F}$ be a proper subset of $\mathbb{C}$. Then $\mathrm{F}$ is a Carleman set for $\mathbb{C}$ if and only if F satisfies the following conditions: a. $\quad \mathbb{C}_{\infty}-\mathrm{F}$ is connected;

b. $\quad \mathbb{C}_{\infty}-\mathrm{F}$ is locally connected at $\infty$;

c. For every compact subset $\mathrm{K}$ of $\mathbb{C}$, there is a neighborhood $V$ of $\infty$ in $\mathbb{C}_{\infty}$ such that no component of $F^{\circ}$ intersects both $K$ and $V$.

Note that the space $\mathbb{C}_{\infty}-\mathrm{F}$ is connected if and only if each component $\mathrm{Z}$ of open set $\mathrm{C}-\mathrm{F}$ is unbounded. 1, This fact, together with Propositionlcan be an excellent tool whether a set is a Carleman set for $\mathbb{C}$. The sets given in the following examples are Carleman sets for $\mathbb{C}$.

Example 1 (Gaier, Page 133 (1987)): The set $\mathrm{E}=\{\mathrm{z} \in \mathbb{C}:|\mathrm{z}|=1, \operatorname{Re} \mathrm{z}>0\} \cup\{\mathrm{z}=\mathrm{x}: \mathrm{x}>$ 1) $\cup \bigcup_{n=3}^{\infty}\left\{z=r e^{i \theta}: r>1, \theta=\pi / n\right\}$ is a Carleman set for $\mathbb{C}$.

Example 2 (Singh, Page 131 (2003)): Let E $=\mathrm{G}_{0} \cup \cup_{n=1}^{\infty}\left(\mathrm{G}_{\mathrm{k}} \cup \mathrm{B}_{\mathrm{k}} \cup \mathrm{L}_{\mathrm{k}} \cup \mathrm{M}_{k}\right)$, where

$$
\begin{aligned}
& \mathrm{G}_{0}=\{\mathrm{z} \in \mathbb{C}:|\mathrm{z}-2| \leq 1\}, \mathrm{G}_{\mathrm{k}}=\{\mathrm{z} \in \mathbb{C}: \mid \mathrm{z}- \\
& (4 \mathrm{k}+2) \mid \leq 1\} \cup\{\mathrm{z} \in \mathbb{C}: \operatorname{Re} \mathrm{z}=4 \mathrm{k}+2, \\
& \mathrm{Imz} \geq 1\} \cup\{\mathrm{z} \in \mathbb{C}: \operatorname{Re} \mathrm{z}=4 \mathrm{k}+2, \mathrm{Imz} \leq \\
& -1\},(\mathrm{k}=1,2,3, \ldots), \mathrm{B}_{\mathrm{k}}=\{\mathrm{z} \in \mathbb{C}: \mid \mathrm{z}+(4 \mathrm{k} \\
& +2) \mid \leq 1\} \cup\{\mathrm{z} \in \mathbb{C}: \operatorname{Re} \mathrm{z}=-(4 \mathrm{k}+2), \operatorname{Im} \\
& \mathrm{z} \geq 1\} \cup\{\mathrm{z} \in \mathbb{C}: \operatorname{Re} \mathrm{z}=-(4 \mathrm{k}+2), \operatorname{Im} \mathrm{z} \\
& \leq-1\},(\mathrm{k}=1,2,3, \ldots), \mathrm{L}_{\mathrm{k}}=\{\mathrm{z} \in \mathbb{C}: \operatorname{Re} \mathrm{z} \\
& =4 \mathrm{k}\},(\mathrm{k}=1,2, \ldots) \text { and } \mathrm{M}_{\mathrm{k}}=\{\mathrm{z} \in \mathbb{C}: \\
& \operatorname{Re} \mathrm{z}=-4 \mathrm{k}\},(\mathrm{k}=1,2,3 \ldots) .
\end{aligned}
$$

Then, by Preposition 1, we can easily show that $\mathrm{E}$ is a Carleman set for $\mathbb{C}$.

\section{Proof of the main result (Theorem 1)}

From the help of the Carleman set of Example 2, Dinesh Kumar, et al., (2016) proved the following result.

Proposition 2: There are transcendental entire functions $\mathrm{f}$ and $\mathrm{g}$ such that there exist an infinite number of domains which lie in the pre-periodic component of the $\mathrm{F}(\mathrm{f}), \mathrm{F}(\mathrm{g})$, $\mathrm{F}(\mathrm{f} \circ \mathrm{g})$ and $\mathrm{F}(\mathrm{g} \circ \mathrm{f})$.

Our main result, that is, Theorem 1 , is an extension of Proposition 2. We proceeds for the following long proof of Theorem 1.

\section{Proof of Theorem 1}

Let,

$\mathrm{E}=\mathrm{G}_{0} \cup \cup_{n=1}^{\infty}\left(\mathrm{G}_{\mathrm{k}} \cup \mathrm{B}_{\mathrm{k}} \cup \mathrm{L}_{\mathrm{k}} \cup \mathrm{M}_{\mathrm{k}}\right)$. 
Then E a Carleman set for $\mathbb{C}$ by Example 2 . By the continuity of an exponential function, for given $\epsilon>0$, there exists $\delta>0$, may depend on a given point $w_{0}$, such that

$\left|\mathrm{w}-\mathrm{w}_{0}\right|<\delta \Rightarrow\left|\mathrm{e}^{\mathrm{w}}-e^{w_{0}}\right|<\epsilon$.

If $\mathrm{w}_{0}=\log \mathrm{t}$, thene $e^{w_{0}}=\mathrm{e}^{\log \mathrm{t}}=\mathrm{t}$. Let us choose $\epsilon=1 / 2$. Then there exist sufficiently small $\delta_{\mathrm{k}}>$ 0 and $\delta_{k^{\prime}}>0$, such that

$|\mathrm{w}-(\pi \mathrm{i}+\log (4 \mathrm{k}-2))|<\delta_{\mathrm{k}} \Rightarrow\left|\mathrm{e}^{\mathrm{w}}+(4 \mathrm{k}-2)\right|<$ $1 / 2,(\mathrm{k}=2,3,4 \ldots)$

and

$|\mathrm{w}-\log (4 \mathrm{k}-2)|<\delta_{k^{\prime}} \Rightarrow\left|\mathrm{e}^{\mathrm{w}}-(4 \mathrm{k}-2)\right|<1 / 2,(\mathrm{k}$ $=1,2,3 \ldots)$

In particular, let us choose sufficiently small $\delta_{0}>0, \delta_{1}>0, \delta_{2}>0, \delta_{1^{\prime}}>0$ and $\delta_{2^{\prime}}>0$ such that

$|\mathrm{w}-\log 2|<\delta_{0} \Rightarrow\left|\mathrm{e}^{\mathrm{w}}-2\right|<1 / 2$.

$|\mathrm{w}-(\pi \mathrm{i}+\log 6)|<\delta_{1} \Rightarrow\left|\mathrm{e}^{\mathrm{w}}+6\right|<1 / 2$.

$|\mathrm{w}-(\pi \mathrm{i}+\log 10)|<\delta_{2} \Rightarrow\left|\mathrm{e}^{\mathrm{w}}+10\right|<1 / 2$.

$|\mathrm{w}-\log 6|<\delta_{1^{\prime}} \Rightarrow\left|\mathrm{e}^{\mathrm{w}}-6\right|<1 / 2$.

$|\mathrm{w}-\log 10|<\delta_{2^{\prime}} \Rightarrow\left|\mathrm{e}^{\mathrm{w}}-10\right|<1 / 2$.

Next, let us define the following functions: $\alpha(\mathrm{z})=$

$\left\{\begin{array}{r}\log 2, \quad \forall \quad z \in \mathrm{G}_{0} \cup \mathrm{U}_{n=1}^{\infty}\left(\mathrm{L}_{k} \cup \mathrm{M}_{\mathrm{k}}\right) ; \\ \pi \mathrm{i}+\log 6, \quad \forall z \in \mathrm{G}_{\mathrm{k}} k=1,2,3, \ldots ; \\ \pi i+\log 10, \\ \pi z \in \mathrm{B}_{1} ; \\ \pi i+(4 k-2), \quad \forall z \in \mathrm{B}_{k}, k=2,3,4 \ldots ;\end{array}\right.$

$\beta(\mathrm{z})=$

$\left\{\begin{array}{rr}\log 2, \quad \forall \quad z \in \mathrm{G}_{0} \cup \mathrm{U}_{n=1}^{\infty}\left(\mathrm{L}_{k} \cup \mathrm{M}_{\mathrm{k}}\right) ; \\ \pi \mathrm{i}+\log 6, & \forall z \in \mathrm{G}_{1} ; \\ \pi \mathrm{i}+\log 10, & \forall z \in \mathrm{B}_{1} ; \\ \log (4 k-2), & \forall z \in \mathrm{G}_{k}, k=2,3,4 \ldots ; \\ \pi i+(4 k-2), & \forall z \in \mathrm{B}_{\mathrm{k},} k=2,3,4, \ldots ;\end{array}\right.$ $\gamma(\mathrm{z})=$

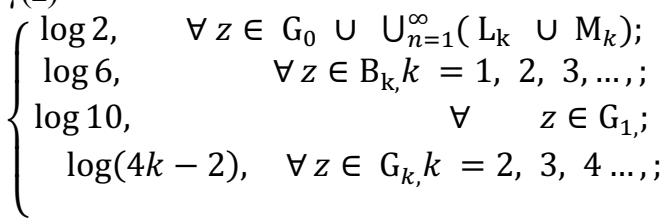

Let us define again the following positive functions:

$$
\begin{aligned}
& \epsilon_{1}(\mathrm{z})= \\
& \left\{\begin{array}{r}
\delta_{0}, \quad \forall z \in \mathrm{G}_{0} \cup \mathrm{\cup}_{n=1}^{\infty}\left(\mathrm{L}_{\mathrm{k}} \cup \mathrm{M}_{k}\right) ; \\
\delta_{1}, \\
\delta_{2},
\end{array}\right. \\
& \delta_{k,} \quad \forall z \in \mathrm{B}_{k}, k=2,3,4 \ldots ; \\
& \epsilon_{2}(\mathrm{z})= \\
& \left\{\begin{array}{rr}
\delta_{0}, & \forall z \in \mathrm{G}_{0} \cup \cup_{n=1}^{\infty}\left(\mathrm{L}_{\mathrm{k}} \cup \mathrm{M}_{\mathrm{k}}\right) ; \\
\delta_{1}, & \forall z \in \mathrm{G}_{1} ; \\
\delta_{2}, & \forall z \in \mathrm{B}_{1} ; \\
\delta_{k}, & \forall z \in \mathrm{B}_{\mathrm{k},}, k=2,3,4 \ldots ; \\
\delta_{k^{\prime}}, & \forall z \in \mathrm{G}_{\mathrm{k},} k=2,3,4 \ldots ;
\end{array}\right. \\
& \epsilon_{3}(\mathrm{z})= \\
& \left\{\begin{array}{rr}
\delta_{0}, & \forall z \in \mathrm{G}_{0} \cup \cup_{n=1}^{\infty}\left(L_{k} \cup \mathrm{M}_{\mathrm{k}}\right) ; \\
\delta_{1^{\prime}}, & \forall z \in \mathrm{B}_{\mathrm{k},} k=1,2,3 \ldots ; \\
\delta_{2}, & \forall z \in \mathrm{G}_{1} ; \\
\delta_{k^{\prime}} & \forall z \in \mathrm{G}_{\mathrm{k},} k=2,3,4 \ldots:
\end{array}\right.
\end{aligned}
$$

Clearly, the functions $\alpha(z), \beta(z)$ and $\gamma(z)$ are piece wise constant functions, so they are continuous on the set $\mathrm{E}$ and analytic in E. ${ }^{\circ}$. Also, since E is a Carleman set, so there exist an entire functions $\mathrm{f}_{1}(\mathrm{z}), \mathrm{g}_{1}(\mathrm{z})$ and $\mathrm{h}_{1}(\mathrm{z})$ such that

$\forall \mathrm{z} \in \mathrm{E},\left|\mathrm{f}_{1}(\mathrm{z})-\alpha(\mathrm{z})\right| \leq \epsilon_{1}(\mathrm{z}),\left|\mathrm{g}_{1}(\mathrm{z})-\beta(\mathrm{z})\right| \leq$ $\epsilon_{2}(\mathrm{z})$ and $\left|\mathrm{h}_{1}(\mathrm{z})-\gamma(\mathrm{z})\right| \leq \epsilon_{3}(\mathrm{z})$.

Consequently, we get transcendental entire functions

$\mathrm{f}(\mathrm{z})=e^{\mathrm{f}_{1}(\mathrm{z})}, \mathrm{g}(\mathrm{z})=e^{g_{1}(\mathrm{z})}$ andh $(\mathrm{z})=e^{h_{1}(\mathrm{z})}$

which respectively satisfy the following:

$|\mathrm{f}(\mathrm{z})-2|<1 / 2, \forall \mathrm{z} \in \mathrm{G}_{0} \cup \bigcup_{n=1}^{\infty}\left(\mathrm{L}_{\mathrm{k}} \cup \mathrm{M}_{k}\right)$;

$|\mathrm{f}(\mathrm{z})+6|<1 / 2, \forall \mathrm{z} \in \mathrm{G}_{\mathrm{k}}, \mathrm{k}=1,2,3 \ldots$;

$|\mathrm{f}(\mathrm{z})+10|<1 / 2, \forall \mathrm{z} \in \mathrm{B}_{1}$;

$|\mathrm{f}(\mathrm{z})+(4 \mathrm{k}-2)|<1 / 2, \quad \forall \mathrm{z} \in \mathrm{B}_{\mathrm{k}}, \mathrm{k}=2,3,4 \ldots$;

$\lg (\mathrm{z})-2 \mid<1 / 2, \forall \mathrm{z} \in \mathrm{G}_{0} \cup \cup_{n=1}^{\infty}\left(\mathrm{L}_{\mathrm{k}} \cup \mathrm{M}_{\mathrm{k}}\right)$;

$|\mathrm{g}(\mathrm{z})+6|<1 / 2, \forall \mathrm{z} \in \mathrm{G}_{1}$;

$|\mathrm{g}(\mathrm{z})+10|<1 / 2, \forall \mathrm{z} \in \mathrm{B}_{1}$;

$|\mathrm{g}(\mathrm{z})+(4 \mathrm{k}-2)|<1 / 2, \quad \forall \mathrm{z} \in \mathrm{B}_{\mathrm{k}}, \mathrm{k}=2,3,4 \ldots ;$

$|\mathrm{g}(\mathrm{z})-(4 \mathrm{k}-2)|<1 / 2, \forall \mathrm{z} \in \mathrm{G}_{\mathrm{k}}, \mathrm{k}=2,3,4 \ldots$;

$|\mathrm{h}(\mathrm{z})-2|<1 / 2, \forall \mathrm{z} \in \mathrm{G}_{0} \cup \cup_{n=1}^{\infty}\left(\mathrm{L}_{\mathrm{k}} \cup \mathrm{M}_{\mathrm{k}}\right)$;

$|\mathrm{h}(\mathrm{z})-6|<1 / 2, \forall \mathrm{z} \in \mathrm{B}_{\mathrm{k}}, \mathrm{k}=1,2,3 \ldots$;

$|\mathrm{h}(\mathrm{z})-10|<1 / 2, \forall \mathrm{z} \in \mathrm{G}_{1}$;

$|\mathrm{h}(\mathrm{z})-(4 \mathrm{k}-2)|<1 / 2, \quad \forall \mathrm{z} \in \mathrm{G}_{\mathrm{k}}, \mathrm{k}=2,3,4 \ldots$;

As we did just above, each of the functions $\mathrm{f}$, $\mathrm{g}$ and $\mathrm{h}$ map the domain $G_{0} \cup \cup_{n=1}^{\infty}\left(\mathrm{L}_{k} \cup\right.$ 
$\mathrm{M}_{k}$ ) into smaller disk $|\mathrm{z}-2|<1 / 2$ contained in $\mathrm{G}_{0}$ and each of this function is a contraction mapping. So, $\quad \mathrm{G}_{0} \cup \cup_{n=1}^{\infty}\left(\mathrm{L}_{\mathrm{k}} \cup\right.$ $M_{k}$ ) contains fixed points $z_{0}, z_{1}$ and $z_{2}$ (say) such that

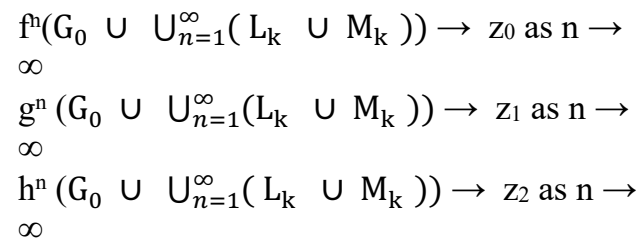

Thefixed points are respectively attracting fixed points for each function $\mathrm{f}, \mathrm{g}$ and $\mathrm{h}$, so $\mathrm{G}_{0} \cup \mathrm{U}_{n=1}^{\infty}\left(\mathrm{L}_{\mathrm{k}} \cup \mathrm{M}_{k}\right)$ lies in attracting cycle, and hence $\mathrm{G}_{0} \cup \cup_{n=1}^{\infty}\left(\mathrm{L}_{\mathrm{k}} \cup \mathrm{M}_{k}\right)$ is a subset of each of the Fatou set F(f), F(g) and $\mathrm{F}(\mathrm{h})$. In this case, $\mathrm{J}(\mathrm{f}) \neq \mathbb{C}, \mathrm{J}(\mathrm{g}) \neq \mathbb{C}$ and $\mathrm{J}(\mathrm{h})$ $\neq \mathbb{C}$ and so Julia set of each of the function $\mathrm{f}$, $\mathrm{g}$ and $\mathrm{h}$ do not contain interior-point and hence Fatou set of each of these function contains all interior points. In such case, Fatou set of each of the function $f, g$ and $h$ contain Carleman set E.

Again, as defined above, function $\mathrm{f}$ maps each $\mathrm{G}_{\mathrm{k}}$ into smaller disk contained in $\mathrm{B}_{1}, \mathrm{~B}_{1}$ into smaller disk contained in $\mathrm{B}_{2}$ and each $\mathrm{Bk}$ for $\mathrm{k}=2,3,4, \ldots$ into the smaller disk contained in $\mathrm{B}_{\mathrm{k}-1}$. $\mathrm{G}_{\mathrm{k}}$ and $\mathrm{B}_{\mathrm{k}}$ are contained in the preperiodic components of Fatou set $\mathrm{F}(\mathrm{f})$ of the function $\mathrm{f}$. Also, as function $\mathrm{g}$ maps each of the domains $G_{k}$ into the smaller disk contained in $\mathrm{G}_{\mathrm{k}-1}(\mathrm{k}=2,3,4, \ldots), \quad \mathrm{G}_{1}$ into smaller disk contained in $\mathrm{B}_{1}, \mathrm{~B}_{1}$ into the smaller disks contained in $\mathrm{B}_{2}$ and $\mathrm{B}_{\mathrm{k}}$ for $\mathrm{k}$ $=2,3,4, \ldots$ into smaller disk contained in $\mathrm{Bk}$ 1. In fact, $G_{k}$ and $B_{k}$ are contained in the preperiodic components of the Fatouset $\mathrm{F}(\mathrm{g})$. Likewise, domains $\mathrm{G}_{\mathrm{k}}$ and $\mathrm{B}_{\mathrm{k}},(\mathrm{k}=1,2,3 \ldots)$ are contained in the pre-periodic components under the function $\mathrm{h}$. Also, note that as we defined above, we can see that domains $\mathrm{B}_{1}$ and $\mathrm{B}_{2}$ lie in the periodic component of both of the functions $\mathrm{f}$ and $\mathrm{g}$. From the above rule, we can say that domains $\mathrm{G}_{1}$ and $\mathrm{G}_{2}$ lie in the periodic component of the function $h$.

Next, we examine the dynamical behavior of compositions of the functions $\mathrm{f}, \mathrm{g}$ and $h$. The composite of any two and all three of these functions satisfy the following:

\section{Dynamical behavior of fo $\mathbf{g}$}

$|(f \circ g)(z)-2|<1 / 2, \forall z \in G_{0} \cup \bigcup_{n=1}^{\infty}\left(L_{k} \cup\right.$ $\left.\mathrm{M}_{k}\right)$;

$\mid\left(\right.$ fog) $(\mathrm{z})+10 \mid<1 / 2, \quad \forall \mathrm{z} \in \mathrm{G}_{1}$;

$|(f \circ g)(z)+6|<1 / 2, \forall z \in G_{k}, k=2,3,4 \ldots$;

$|(f \circ g)(z)+6|<1 / 2, \quad \forall z \in B_{1}$;

$|(f \circ g)(z)+10|<1 / 2, \quad \forall z \in B_{2}$;

$|(f \circ g)(z)+(4 k-6)|<1 / 2, \forall z \in B_{k}, k=2,3,4 \ldots$;

This composition rule shows that the domains $\mathrm{G}_{0} \cup \cup_{n=1}^{\infty}\left(\mathrm{L}_{\mathrm{k}} \cup \mathrm{M}_{k}\right), \mathrm{G}_{\mathrm{k}}$ and $\mathrm{B}_{\mathrm{k}}$, $(\mathrm{k}=1,2,3, \ldots)$ belong to $\mathrm{F}(\mathrm{f} \circ \mathrm{g})$ and in fact, each $G_{k}$ and $B_{k}$ for each $k \in \mathbb{N}$ is contained in the pre-periodic components of $F(f \circ g)$. In particular, $\mathrm{B}_{1}$ and $\mathrm{B}_{2}$ is contained in the periodic component of period 1 under the function fog.

\section{Dynamical behavior of $g \circ \mathbf{f}$}

$|(\mathrm{g} \circ \mathrm{f})(\mathrm{z})-2|<1 / 2, \forall \mathrm{z} \in \mathrm{G}_{0} \cup \cup_{n=1}^{\infty}\left(\mathrm{L}_{\mathrm{k}} \quad \cup\right.$ $\left.\mathrm{M}_{\mathrm{k}}\right)$

$|(\mathrm{g} \circ \mathrm{f})(\mathrm{z})+10|<1 / 2, \forall \mathrm{z} \in \mathrm{G}_{\mathrm{k}}, \mathrm{k}=1,2,3$,

$4 \ldots$

$|(\mathrm{g} \circ \mathrm{f})(\mathrm{z})+6|<1 / 2, \forall \mathrm{z} \in \mathrm{B}_{1}$;

$|(\mathrm{g} \circ \mathrm{f})(\mathrm{z})+10|<1 / 2, \quad \forall \mathrm{z} \in \mathrm{B}_{2}$;

$|(\mathrm{g} \circ \mathrm{f})(\mathrm{z})+(4 \mathrm{k}-6)|<1 / 2, \forall \mathrm{z} \in \mathrm{B}_{\mathrm{k}}, \mathrm{k}=3,4$,

$5 \ldots$;

From this composition rule, we can say that the domains $\mathrm{G}_{0} \cup \mathrm{U}_{n=1}^{\infty}\left(\mathrm{L}_{k} \cup \mathrm{M}_{k}\right)$ and $\mathrm{B}_{\mathrm{k}}$, $(\mathrm{k}=1,2,3, \ldots)$ belong to $\mathrm{F}(\mathrm{g} \circ \mathrm{f})$ and in fact, each $G_{k}$ and $B_{k}$ for each $k \in \mathbb{N}$ is contained in the pre-periodic domain of $\mathrm{F}(\mathrm{f} \circ \mathrm{g})$.In particular, each $\mathrm{B}_{1}$ and $\mathrm{B}_{2}$ is contained in the periodic component of period 1 under the function gof.

\section{Dynamical behavior of $\mathbf{f} \circ \mathbf{h}$}

$|(f \circ h)(z)-2|<1 / 2, \forall z \in G_{0} \cup \bigcup_{n=1}^{\infty}\left(L_{k} \cup\right.$ $\left.\mathrm{M}_{k}\right)$

$\mid\left(\right.$ fo h) $(\mathrm{z})+6 \mid<1 / 2, \quad \forall \quad \mathrm{z} \in \mathrm{G}_{1}$;

$|(f \circ h)(z)+6|<1 / 2, \forall z \in G_{k}, k=2,3,4 \ldots$;

$|(f \circ h)(z)+6|<1 / 2, \forall z \in B_{k}, k=1,2,3 \ldots$;

As we defined in the above composition rule, the domains $\mathrm{G}_{0} \cup \cup_{n=1}^{\infty}\left(\mathrm{L}_{\mathrm{k}} \cup \mathrm{M}_{k}\right)$ and $\mathrm{B}_{\mathrm{k}},(\mathrm{k}=1,2,3 \ldots)$ belong to $\mathrm{F}(\mathrm{f} \circ \mathrm{h})$. In fact, each $G_{k}$ and $B_{k}$ for all $k=1,2,3, \ldots$ contained in the pre-periodic components of $\mathrm{F}(\mathrm{f} \circ \mathrm{h})$.

\section{Dynamical behavior of $h \circ f$}

$$
\begin{aligned}
& |(\mathrm{h} \circ \mathrm{f})(\mathrm{z})-2|<1 / 2, \forall \mathrm{z} \in \mathrm{G}_{0} \cup \\
& \bigcup_{n=1}^{\infty}\left(\mathrm{L}_{\mathrm{k}} \cup \mathrm{M}_{\mathrm{k}}\right)
\end{aligned}
$$


$|(\mathrm{h} \circ \mathrm{f})(\mathrm{z})-6|<1 / 2, \forall \mathrm{z} \in \mathrm{G}_{\mathrm{k}}, \mathrm{k}=1,2,3 \ldots$;

$|(\mathrm{h} \circ \mathrm{g})(\mathrm{z})-6|<1 / 2, \forall \mathrm{z} \in \mathrm{B}_{\mathrm{k}}, \mathrm{k}=2,3,4 \ldots$;

$|(\mathrm{h} \circ \mathrm{g})(\mathrm{z})-6|<1 / 2, \forall \mathrm{z} \in \mathrm{B}_{1}$;

From this composition rule, we can say that the domains $\mathrm{G}_{0} \cup \mathrm{U}_{n=1}^{\infty}\left(\mathrm{L}_{k} \cup \mathrm{M}_{k}\right), \mathrm{G}_{\mathrm{k}}$ and $\mathrm{B}_{\mathrm{k},}(\mathrm{k}=1,2,3 \ldots)$ belong to $\mathrm{F}(\mathrm{h} \circ \mathrm{f})$. In fact, each $G_{k}$ and $B_{k}$, for all $k=1,2,3 \ldots$ is contained in the pre-periodic component of $F(h \circ f)$.

\section{Dynamical behavior of $\mathbf{g} \circ \mathbf{h}$ \\ $|(\mathrm{g} \circ \mathrm{h})(\mathrm{z})-2|<1 / 2, \forall \mathrm{z} \in \mathrm{G}_{0} \mathrm{U}$ $\mathrm{U}_{n=1}^{\infty}\left(\mathrm{L}_{\mathrm{k}} \cup \mathrm{M}_{\mathrm{k}}\right)$; \\ $\mid\left(\right.$ go h) $(\mathrm{z})-6 \mid<1 / 2, \quad \forall \mathrm{z} \in \mathrm{G}_{1}$; \\ $|(\mathrm{g} \circ \mathrm{h})(\mathrm{z})+6|<1 / 2, \forall \mathrm{z} \in \mathrm{G}_{\mathrm{k}}, \mathrm{k}=2,3,4 \ldots$; $|(\mathrm{g} \circ \mathrm{h})(\mathrm{z})+6|<1 / 2, \forall \mathrm{z} \in \mathrm{B}_{\mathrm{k}}, \mathrm{k}=1,2,3 \ldots$; \\ As we defined in the above composition rule, the domains $\mathrm{G}_{0} \cup \cup_{n=1}^{\infty}\left(\mathrm{L}_{\mathrm{k}} \cup \mathrm{M}_{\mathrm{k}}\right)$, $\mathrm{G}_{\mathrm{k}}$ and $\mathrm{B}_{\mathrm{k}},(\mathrm{k}=1,2,3 \ldots)$ belong to $\mathrm{F}(\mathrm{g} \circ \mathrm{h})$. In fact, each $G_{k}$ and $B_{k}$, for all $k=1,2,3, \ldots$ is contained in the pre-periodic component of $F(h \circ f)$.}

\section{Dynamical behavior of $\mathbf{h} \circ \mathbf{g}$}

$|(\mathrm{h} \circ \mathrm{g})(\mathrm{z})-2|<1 / 2, \forall \mathrm{z} \in \mathrm{G}_{0} \cup \cup_{n=1}^{\infty}\left(\mathrm{L}_{\mathrm{k}} \quad \mathrm{U}\right.$ $\left.\mathrm{M}_{\mathrm{k}}\right)$;

$|(h \circ g)(z)-6|<1 / 2, \forall z \in G_{1}$;

$|(h \circ g)(z)-10|<1 / 2, \forall z \in G_{2}$;

$|(\mathrm{h} \circ \mathrm{g})(\mathrm{z})-(4 \mathrm{k}-6)|<1 / 2, \quad \forall \mathrm{z} \in \mathrm{B}_{\mathrm{k}}, \mathrm{k}$

$=3,4,5, \ldots$;

$|(\mathrm{h} \circ \mathrm{g})(\mathrm{z})-6|<1 / 2, \forall \mathrm{z} \in \mathrm{B}_{\mathrm{k}}, \mathrm{k}=1,2,3, \ldots$;

From this composition, we can say that the domains $\mathrm{G}_{0} \cup \mathrm{U}_{n=1}^{\infty}\left(\mathrm{L}_{\mathrm{k}} \cup \mathrm{M}_{\mathrm{k}}\right), \mathrm{G}_{\mathrm{k}}$ and $\mathrm{B}_{\mathrm{k}},(\mathrm{k}=1,2,3 \ldots)$ belong to $\mathrm{F}(\mathrm{h} \circ \mathrm{g})$. In fact, each $G_{k}$ and $B_{k}$, for all $k=1,2,3 \ldots$ is contained in the pre-periodic component of $\mathrm{F}(\mathrm{h} \circ \mathrm{f})$. In particular, each $G_{1}$ and $G_{2}$ is periodic component of period 1 under the function ho f.

\section{Dynamical behavior of fo $g \circ \mathbf{h}$}

$|(\mathrm{f} \circ \mathrm{g} \circ \mathrm{h})(\mathrm{z})-2|<1 / 2, \forall \mathrm{z} \in \mathrm{G}_{0} \mathrm{U}$ $\mathrm{U}_{n=1}^{\infty}\left(\mathrm{L}_{\mathrm{k}} \cup \mathrm{M}_{\mathrm{k}}\right)$;

$|(f \circ g \circ h)(z)+10|<1 / 2, \forall z \in B_{k}, k=1,2$,

$3 \ldots$;

$|(f \circ g \circ h)(z)+6|<1 / 2, \forall z \in G_{1}$;

$|(f \circ g \circ h)(z)+10|<1 / 2, \quad \forall z \in G_{2}$;

$|(f \circ g \circ h)(z)+6|<1 / 2, \forall z \in G_{k}, k=3,4,5 \ldots$;

The composition rule assigned above tells us those domains $G_{0} \cup \cup_{n=1}^{\infty}\left(L_{k} \cup M_{k}\right) G_{k}$ and $B_{k},(k=1,2,3 \ldots)$ lie in $F(f \circ g \circ h)$. In fact, each $G_{k}$ and $B_{k}$ for all $k=1,2,3 \ldots$ is contained in the pre-periodic component of $F(f \circ g \circ h)$.

\section{Dynamical behavior of $\mathbf{f} \circ \mathbf{h} \circ \mathbf{g}$}

$|(f \circ h \circ g)(z)-2|<1 / 2, \forall z \in G_{0} \cup$ $\mathrm{U}_{n=1}^{\infty}\left(\mathrm{L}_{\mathrm{k}} \cup \mathrm{M}_{\mathrm{k}}\right)$;

$|(\mathrm{f} \circ \mathrm{h} \circ \mathrm{g})(\mathrm{z})+6|<1 / 2, \quad \forall \mathrm{z} \in \mathrm{G}_{1}$;

$|(f \circ h \circ g)(z)+6|<1 / 2, \quad \forall z \in G_{2}$;

$|(f \circ h \circ g)(z)+6|<1 / 2, \forall z \in G_{k}, k=3,4$,

$5 \ldots$;

$|(f \circ h \circ g)(z)+6|<1 / 2, \quad \forall z \in B_{2}$;

$|(f \circ h \circ g)(z)+6|<1 / 2, \forall z \in B_{k}, k=2,3$,

$4 \ldots$;

The composition rule assigned above tells us that domains $\quad \mathrm{G}_{0} \cup \cup_{n=1}^{\infty}\left(\mathrm{L}_{\mathrm{k}} \cup \mathrm{M}_{\mathrm{k}}\right)$, Gkand $B_{k},(k=1,2,3, \ldots)$ lie in $F(f \circ h \circ g)$ and in fact, each $G_{k}$ and $B_{k},(k=1,2,3, \ldots)$ is contained in the pre-periodic component of $\mathrm{F}(\mathrm{f} \circ \mathrm{h} \circ \mathrm{g})$. In particular, domain $\mathrm{B}_{1}$ is contained in the periodic component under the function fo ho $\mathrm{g}$.

\section{Dynamical behavior of $\mathbf{g} \bullet \mathbf{f} \circ \mathbf{h}$}

$\mid\left(\mathrm{g} \circ\right.$ fo h) $(\mathrm{z})-2 \mid<1 / 2, \forall \mathrm{z} \in \mathrm{G}_{0} \mathrm{U}$ $\mathrm{U}_{n=1}^{\infty}\left(\mathrm{L}_{\mathrm{k}} \cup \mathrm{M}_{\mathrm{k}}\right)$;

$|(\mathrm{g} \circ \mathrm{f} \circ \mathrm{h})(\mathrm{z})+10|<1 / 2, \forall \mathrm{z} \in \mathrm{G}_{\mathrm{k}}, \mathrm{k}=1,2,3 \ldots$;

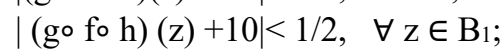

$|(\mathrm{g} \circ \mathrm{f} \circ \mathrm{h})(\mathrm{z})+10|<1 / 2, \forall \mathrm{z} \in \mathrm{B}_{\mathrm{k}}, \mathrm{k}=2,3$, $4 \ldots$;

The composition rule assigned above tells us that domains $G_{0} \cup \bigcup_{n=1}^{\infty}\left(L_{k} \cup\right.$ $\left.\mathrm{M}_{\mathrm{k}}\right), \mathrm{G}_{\mathrm{k}}$ and $\mathrm{B}_{\mathrm{k}},(\mathrm{k}=1,2,3, \ldots)$ lie in $\mathrm{F}(\mathrm{g}$ 。 fo $h$ ). In fact, each $G_{k}$ and $B_{k}$, for all $k=1,2$, $3, \ldots$ is contained in the pre-periodic component of $\mathrm{F}(\mathrm{g} \circ \mathrm{f} \circ \mathrm{h})$. In particular, domain $\mathrm{B}_{2}$ is contained in the periodic component under the function $\mathrm{g} \circ \mathrm{f} \circ \mathrm{h}$.

\section{Dynamical behavior of $\mathbf{g} \circ \mathbf{h} \bullet \mathbf{f}$}

$|(g \circ h \circ f)(z)-2|<1 / 2, \forall z \in G_{0} U$ $\mathrm{U}_{n=1}^{\infty}\left(\mathrm{L}_{\mathrm{k}} \cup \mathrm{M}_{\mathrm{k}}\right)$;

$|(\mathrm{g} \circ \mathrm{h} \circ \mathrm{f})(\mathrm{z})+6|<1 / 2, \forall \mathrm{z} \in \mathrm{G}_{\mathrm{k}}, \mathrm{k}=1,2,3$, ...;

$|(\mathrm{g} \circ \mathrm{h} \circ \mathrm{f})(\mathrm{z})+6|<1 / 2, \quad \forall \mathrm{z} \in \mathrm{B}_{1}$;

$|(\mathrm{g} \circ \mathrm{h} \circ \mathrm{f})(\mathrm{z})+6|<1 / 2, \forall \mathrm{z} \in \mathrm{B}_{\mathrm{k}}, \mathrm{k}=2,3,4 \ldots$; The composition rule assigned above tells us that domains $\mathrm{G}_{0} \cup \mathrm{U}_{n=1}^{\infty}\left(\mathrm{L}_{\mathrm{k}} \cup \mathrm{M}_{\mathrm{k}}\right), \mathrm{G}_{\mathrm{k}}$ and $B_{k},(k=1,2,3 \ldots)$ lie in $F(g \circ h \circ f)$. In 
fact, each $G_{k}$ and $B_{k}$, for all $k=1,2,3, \ldots$ is contained in the pre-periodic component of $\mathrm{F}(\mathrm{g} \circ \mathrm{h} \circ \mathrm{f})$. In particular, domain $\mathrm{B}_{1}$ is contained in the periodic component under the function $\mathrm{g} \circ \mathrm{f} \circ \mathrm{h}$.

\section{Dynamical behavior of $\mathbf{h} \circ \mathbf{f} \circ \mathbf{g}$

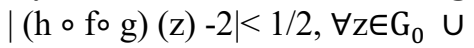 $\mathrm{U}_{n=1}^{\infty}\left(\mathrm{L}_{\mathrm{k}} \cup \mathrm{M}_{\mathrm{k}}\right)$; \\ $|(\mathrm{h} \circ \mathrm{f} \circ \mathrm{g})(\mathrm{z})-6|<1 / 2, \forall \mathrm{z} \in \mathrm{G}_{\mathrm{k}}, \mathrm{k}=2,3,4 \ldots$; \\ $|(h \circ f \circ g)(z)-6|<1 / 2, \forall z \in G_{1}$; \\ $|(h \circ f \circ g)(z)-6|<1 / 2, \quad \forall z \in B_{1}$; \\ $|(h \circ f \circ g)(z)-6|<1 / 2, \quad \forall z \in B_{2}$; \\ $|(\mathrm{h} \circ \mathrm{f} \circ \mathrm{g})(\mathrm{z})-6|<1 / 2, \forall \mathrm{z} \in \mathrm{B}_{\mathrm{k}}, \mathrm{k}=3,4,5 \ldots$; \\ The composition assigned above tells us that domains $G_{0} \cup \cup_{n=1}^{\infty}\left(L_{k} \cup M_{k}\right)$, Gkand $\mathrm{B}_{\mathrm{k}}$, $(\mathrm{k}=1,2,3 \ldots)$ lie in $\mathrm{F}(\mathrm{h} \circ \mathrm{f} \circ \mathrm{g})$. In fact, each $\mathrm{G}_{\mathrm{k}}$ and $\mathrm{B}_{\mathrm{k}}$ for all $\mathrm{k}=1,2,3, \ldots$ is contained in the pre-periodic component of $\mathrm{F}(\mathrm{h} \circ \mathrm{f} \circ \mathrm{g}$ ). In particular, domain $G_{1}$ is contained in the periodic component under the function ho fo g.}

\section{Dynamical behavior of $\mathbf{h} \circ \mathbf{g} \circ \mathbf{f}$

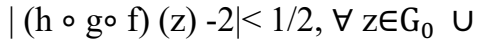 $\cup_{n=1}^{\infty}\left(\mathrm{L}_{\mathrm{k}} \cup \mathrm{M}_{\mathrm{k}}\right)$; \\ $|(\mathrm{h} \circ \mathrm{g} \circ \mathrm{f})(\mathrm{z})-6|<1 / 2, \forall \mathrm{z} \in \mathrm{G}_{\mathrm{k}}, \mathrm{k}=1,2,3, \ldots$; \\ $|(h \circ \mathrm{g} \circ \mathrm{f})(\mathrm{z})-6|<1 / 2, \quad \forall \mathrm{z} \in \mathrm{B}_{1}$; \\ $|(h \circ g \circ f)(z)-6|<1 / 2, \forall z \in B_{k}, k=2,3,4, \ldots$;}

The composition rule assigned above tells us that domains $\mathrm{G}_{0} \cup \mathrm{U}_{n=1}^{\infty}\left(\mathrm{L}_{\mathrm{k}} \cup \mathrm{M}_{\mathrm{k}}\right), \mathrm{G}_{\mathrm{k}}$ and $B_{k},(k=1,2,3, \ldots)$ lie in $F(h \circ g \circ f)$. In fact, each $G_{k}$ and $B_{k}$, for all $k=1,2,3, \ldots$ is contained in the pre-periodic component of $F(h \circ g \circ f)$. In particular, domain $G_{1}$ is contained in the periodic component under the function $\mathrm{h} \circ \mathrm{f} \circ \mathrm{g}$.

From all of the above discussion, we found that the domains $\mathrm{G}_{\mathrm{k}}$ and $\mathrm{B}_{\mathrm{k}}$ for all $\mathrm{k}=$ $1,2,3, \ldots$ contained in the pre-periodic domains of the functions $\mathrm{f}, \mathrm{g}, \mathrm{h}$ and their compositions.

\section{Acknowledgements}

This research work of the first author is supported by a $\mathrm{PhD}$ faculty fellowship of the University Grants Commission, Nepal.

\section{References}

Gaier, A., 1987. Lectures on complex approximation, Birkhauser.

Kumar, D. Dutt, G. and Kumar, S., 2015. Dynamics of composite entire functions. J. Indian Math. Soc., 82(3-4). 107-114.

Singh, A. P., 2003. On the dynamics of composite entire functions. Math. Proc. Camb. Phil. Soc. 134: 129-138.

Subedi, B.H., 2019. Dynamics on the wandering components of the Fatou set of three transcendental entire functions and their compositions. The Indian Journal of Mathematics, 61(3). 329-392. arXiv: 1803.09259v1 [math. DS]. 